\title{
Celastrol inhibits aminoglycoside-induced ototoxicity via heat shock protein 32
}

\author{
SP Francis ${ }^{1}$, II Kramarenko ${ }^{1}$, CS Brandon ${ }^{1}$, F-S Lee ${ }^{2}$, TG Baker ${ }^{1}$ and LL Cunningham ${ }^{\star 3}$
}

Hearing loss is often caused by death of the mechanosensory hair cells of the inner ear. Hair cells are susceptible to death caused by aging, noise trauma, and ototoxic drugs, including the aminoglycoside antibiotics and the antineoplastic agent cisplatin. Ototoxic drugs result in permanent hearing loss for over 500000 Americans annually. We showed previously that induction of heat shock proteins (HSPs) inhibits both aminoglycoside- and cisplatin-induced hair cell death in whole-organ cultures of utricles from adult mice. In order to begin to translate these findings into a clinical therapy aimed at inhibiting ototoxic drug-induced hearing loss, we have now examined a pharmacological HSP inducer, celastrol. Celastrol induced upregulation of HSPs in utricles, and it provided significant protection against aminoglycoside-induced hair cell death in vitro and in vivo. Moreover, celastrol inhibited hearing loss in mice receiving systemic aminoglycoside treatment. Our data indicate that the major heat shock transcription factor HSF-1 is not required for celastrol-mediated protection. HSP32 (also called heme oxygenase-1, HO-1) is the primary mediator of the protective effect of celastrol. HSP32/HO-1 inhibits pro-apoptotic c-Jun N-terminal kinase (JNK) activation and hair cell death. Taken together, our data indicate that celastrol inhibits aminoglycoside ototoxicity via HSP32/HO-1 induction.

Cell Death and Disease (2011) 2, e195; doi:10.1038/cddis.2011.76; published online 25 August 2011

Subject Category: Experimental Medicine

Aminoglycoside antibiotics are among the most commonly used antibiotics worldwide. ${ }^{1}$ Although aminoglycosides are highly effective antimicrobial agents, their use has serious side effects, including ototoxicity. ${ }^{1}$ Aminoglycoside exposure results in apoptotic death of the mechanosensory hair cells of the inner ear. ${ }^{2-4}$ Estimates of the incidence of ototoxicity in individuals undergoing aminoglycoside treatment range from 3 to $33 \% .{ }^{5}$ The resulting aminoglycoside-induced hearing loss and/or balance disturbance is irreparable. ${ }^{1}$

Numerous studies indicate that both reactive oxygen species (ROS) formation, and activation of C-Jun $\mathrm{N}$-terminal kinase (JNK) are critical mediators of aminoglycoside-induced hair cell death. ${ }^{6-8}$ Gentamicin forms a redox complex with free iron, which is capable of catalyzing the formation of ROS, including the highly reactive hydroxyl radical and lipid peroxidation products. $^{8}$ Evidence for the importance of oxidative injury in aminoglycoside-induced ototoxicity comes from studies showing that antioxidants protect hair cells against aminoglycoside-induced death. ${ }^{9} \mathrm{~A}$ second critical mediator of aminoglycoside-induced hair cell death is $\mathrm{JNK}^{7}$ Inhibition of JNK using either small molecules or cell permeable peptides protects hair cells and preserves hearing. ${ }^{7,10}$ Although previous clinical studies have demonstrated protective effects of both salicylate and $\mathrm{N}$-acetylcysteine against aminoglycoside ototoxicity, there are currently no co-therapies in widespread clinical use for prevention of aminoglycoside ototoxicity.

Heat shock proteins (HSPs) are abundant cellular constituents that function as molecular chaperones, promoting proper protein folding, localization, and function. ${ }^{11}$ Induction of HSP expression is a highly conserved cellular response to stress and injury. HSPs confer robust cytoprotection and inhibit various apoptotic signaling proteins, making them potential therapeutic targets for the treatment of a variety of diseases. Evidence for HSP-mediated protection in the inner ear initially came from studies in mice exposed to noise trauma. Total body heat stress (hyperthermia) resulted in HSP induction and significant protection against noise-induced hearing loss, ${ }^{12}$ suggesting that HSP induction can protect sensory hair cells under stress.

We showed that heat shock inhibits both aminoglycosideand cisplatin-induced hair cell death in whole-organ cultures of utricles from adult mice. ${ }^{13}$ HSP70 is necessary for this protective effect, and constitutive expression of HSP70 is protective against aminoglycoside-induced hair cell death. ${ }^{14}$ Importantly, HSP70 also protects against hearing loss in mice exposed to systemic kanamycin. ${ }^{15}$ Taken together, these data indicate that HSP induction is a critical stress response in the inner ear that can promote survival of hair cells exposed to major stressors. Cisplatin-induced hair cell death is inhibited

\footnotetext{
${ }^{1}$ Department of Pathology and Laboratory Medicine, Medical University of South Carolina, Charleston, SC, USA; ${ }^{2}$ Department of Otolaryngology-HNS, Medical University of South Carolina, Charleston, SC, USA and ${ }^{3}$ National Institute on Deafness and Other Communication Disorders, National Institutes of Health, 5 Research Court, Rockville, MD, USA

${ }^{*}$ Corresponding author: LL Cunningham, National Institute on Deafness and Other Communication Disorders, National Institutes of Health, 5 Research Court, Rockville, MD 20850, USA. Tel: 301443 2766; Fax: 301402 4200; E-mail: lisa.cunningham @ nih.gov

Keywords: ototoxicity; hair cell; celastrol; heat shock protein; utricle; cochlea; hearing loss

Abbreviations: HSPs, heat shock proteins; HSP32, heat shock protein 32; HO-1, heme oxygenase 1; ROS, reactive oxygen species; JNK, c-Jun N-terminal kinase; CO, carbon monoxide; Hsf-1, heat shock transcription factor 1; Nrf-2, NF-E2-related factor-2; ZnPPIX, zinc protoporphyrin IX; CoPPIX, cobalt protoporphyrin IX; ABR, auditory brainstem response; CORM2, tricarbonyldichlororuthenium (II) dimer

Received 28.4.11; revised 15.6.11; accepted 28.6.11; Edited by V De Laurenzi
} 
by HSP32, also known as heme oxygenase-1 (HO-1). ${ }^{16}$ $\mathrm{HSP} 32 / \mathrm{HO}-1$ is an enzyme that catalyzes the breakdown of heme into bilirubin, carbon monoxide (CO), and free iron. ${ }^{17}$ Both bilirubin and $\mathrm{CO}$ are cytoprotective in the inner ear as well as in other model systems. ${ }^{16}$ Thus, HSP induction may hold potential as a clinical co-therapy aimed at inhibiting ototoxic hair cell death and hearing loss.

Methods for inducing the heat shock response in humans have been available for some time, but these often elicit inadequate heating of the target area, or they are poorly tolerated. ${ }^{18}$ Therefore, pharmacological induction of HSPs may be a more clinically feasible approach for protecting cells under stress. Recently, a consortium of 26 laboratories cooperated on a screen of the Federal Drug Administration (FDA)-approved drugs and bioactive compounds in order to identify compounds that activate the heat shock response. ${ }^{19}$ Of these compounds, celastrol was recognized as 'of particular interest' because it was independently identified in five participating laboratories. ${ }^{19}$ Celastrol induces HSPs via activation of the major heat shock transcription factor (Hsf-1). In addition, celastrol is cytoprotective. ${ }^{19}$ Celastrol is a triterpene compound that is one of several bioactive molecules in extracts from the plant Tripterygium wilfordii. Extracts from this plant have been used for many years in traditional Chinese medicine to treat chills, joint pain, and arthritis. Celastrol has antioxidant and anti-inflammatory properties in addition to being an inducer of the heat shock response. ${ }^{20}$ Celastrol is neuroprotective, anti-angiogenic and anti-tumorogenic in mouse models. ${ }^{21}$ Here we have investigated celastrol's potential to inhibit aminoglycoside-induced hair cell death and hearing loss, and we have examined the mechanisms underlying the protective effect of celastrol.

\section{Results}

Celastrol induces heat shock mRNA and protein expression. To determine whether celastrol induces HSP mRNA expression, utricles were incubated in celastrol $(1.5 \mu \mathrm{M})$ for $3 \mathrm{~h}$ and allowed to recover in culture medium for various times. mRNA was analyzed by real-time quantitative RT-PCR (Figure 1a). Immediately after incubation in celastrol, HSP70 mRNA levels had increased to more than 18-fold above control. At $3 \mathrm{~h}$ post celastrol incubation, HSP70 levels had decreased to $\sim 3$-fold above control, and levels continued to decrease thereafter. HSP32/HO-1 mRNA levels peaked $3 \mathrm{~h}$ post celastrol incubation ( $\sim 18$-fold higher than control expression). mRNA levels of both HSP27 and HSP90 were slightly elevated by celastrol. These data indicate that celastrol results in robust upregulation of HSP70 and HSP32/HO-1 mRNA in utricles. Western blot analysis was then used to examine celastrol's effect on HSP protein levels (Figure 1b). Heat-shocked $\left(43^{\circ} \mathrm{C}\right.$ for $30 \mathrm{~min}$ ) utricles were used as positive controls for HSP induction. HSP70 expression levels in celastrol-treated utricles were comparable to those induced by heat shock. Celastrol-induced HSP32/HO-1 expression was significantly higher than that in heat-shocked utricles. HSP27 expression was less than that induced by heat shock but increased relative to control. HSP90 expression remained relatively unchanged in both heat-shocked and celastrol-treated utricles. These data indicate that celastrol induces robust upregulation of both HSP32/HO-1 and HSP70.

Celastrol inhibits aminoglycoside-induced hair cell death. Utricles were incubated in celastrol and neomycin, and Myosin VIIA immunochemistry was used to label hair cells (Figures 1c-f). Treatment with celastrol alone (Figure 1d) did not result in hair cell loss relative to utricles cultured in control media (Figure 1c). Neomycin resulted in significant loss of hair cells (Figures 1e and g). Celastrol significantly attenuated hair cell death induced by neomycin (Figures 1f and $\mathrm{g}$ ). We tested celastrol's protective effect at a range of neomycin doses (Figure 1g). Celastrol had a significant protective effect against neomycin-induced hair cell death across the dose-response relationship (2-way ANOVA $\left.F_{1,132}=28.916, P<0.001\right)$.

Celastrol inhibits aminoglycoside-induced JNK activation. Aminoglycoside-induced hair cell apoptosis is mediated by JNK. ${ }^{7,10}$ In order to begin to examine the mechanisms underlying the protective effect of celastrol, we studied the effects of celastrol on JNK activation (Figure 1h). Utricles were treated with celastrol before treatment with neomycin for $12 \mathrm{~h}$. JNK activation was analyzed using an antibody that is specific for dually phosphorylated JNK. Control utricles displayed little JNK activation. Neomycin resulted in a robust increase in JNK phosphorylation, and this increase was inhibited by celastrol. These data indicate that celastrol inhibits pro-apoptotic JNK signaling in neomycin-exposed utricles.

Hsf-1 is not required for celastrol's protective effect. Celastrol activates the major heat shock transcription factor Hsf- $1,{ }^{19}$ and the protective effect of heat shock against aminoglycoside-induced hair cell death is dependent on Hsf-1. ${ }^{14}$ To determine whether Hsf-1 is required for the protective effect of celastrol against aminoglycoside-induced hair cell death, we utilized utricles from $\mathrm{Hsf}_{-1} \mathrm{1}^{-1-}$ mice and their wild-type littermates (Figure 2a). Utricles were cultured in (1) control media, (2) celastrol, (3) gentamicin, or (4) celastrol plus gentamicin. Control utricles of both genotypes had similar hair cell counts. Gentamicin resulted in significant hair cell death in utricles from both $\mathrm{Hsf}-1^{+/+}$ and $\mathrm{Hsf}-1^{-/}$mice. Celastrol provided significant protection against gentamicin-induced hair cell death in both $\mathrm{Hsf}-\mathrm{1}^{+/+}$ and $H s f-1^{-/}$utricles (3-way ANOVA $F_{1,59}=34.24$, $P<0.001)$. These data indicate that the protective effect of celastrol does not require Hsf-1.

Celastrol induces HSP32 expression in the absence of Hsf-1. As $\mathrm{Hsf}-1^{-1-}$ utricles were protected by celastrol, we next examined whether celastrol induces HSP expression in the absence of Hsf-1. HSP70 and HSP32/HO-1 mRNA levels were analyzed in $\mathrm{Hsf}_{-1} \mathrm{1}^{+/+}$and $\mathrm{Hsf}-\mathrm{1}^{-1-}$ utricles treated with celastrol (Figure 2b). In $\mathrm{Hsf}_{-1} \mathrm{1}^{+/+}$ utricles, celastrol resulted in $\sim 100$-fold increase in HSP70 mRNA expression and $\sim 17$-fold increase in $\mathrm{HSP} 32 \mathrm{HO}-1$ mRNA. Celastrol did not induce HSP70 in $\mathrm{Hsf-1^{-1 } -}$ utricles. However, celastrol did induce HSP32/HO-1 mRNA 

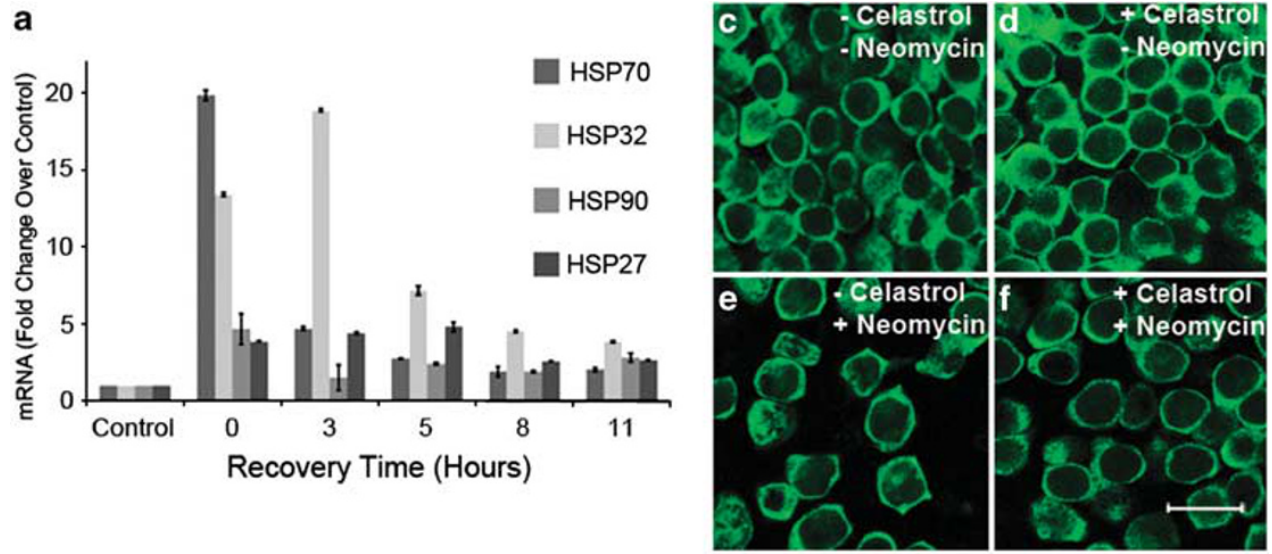

b g
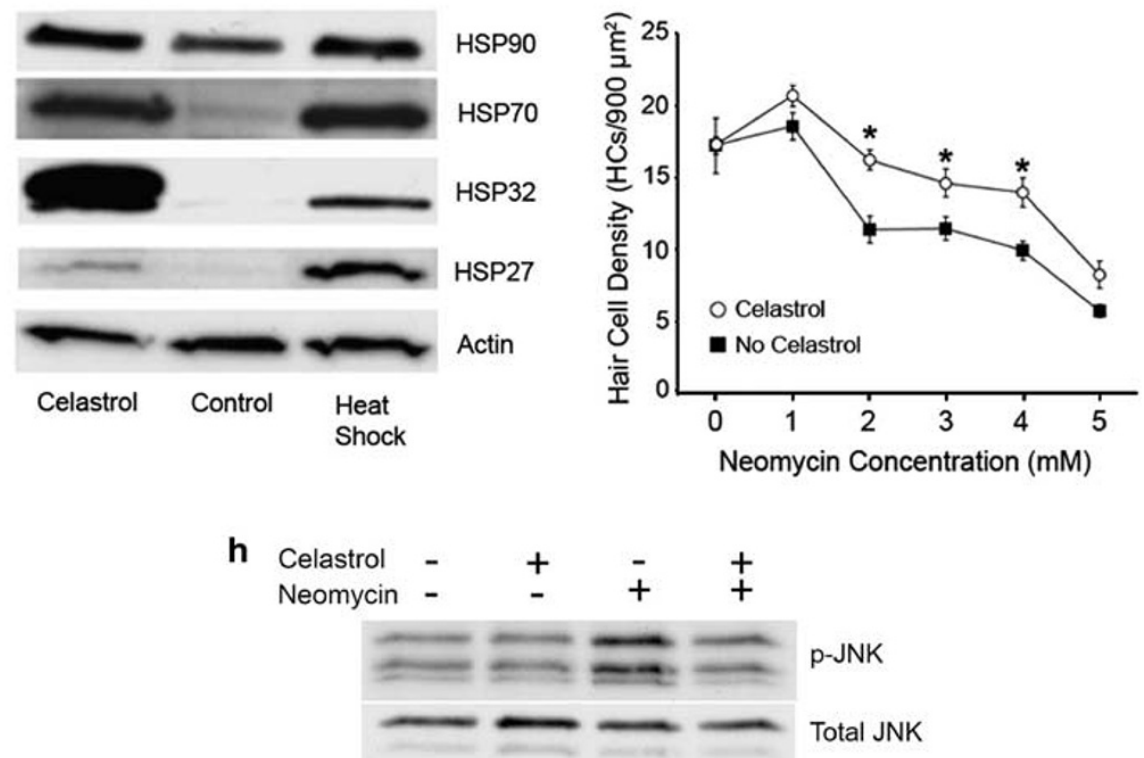

Figure 1 Celastrol induces HSPs and inhibits aminoglycoside-induced hair cell death. (a) RT-PCR analysis of HSP mRNA expression. Utricles were treated with (or without) celastrol for $3 \mathrm{~h}$ and allowed to recover for $0-11 \mathrm{~h}$. Celastrol resulted in robust upregulation of HSP70 and HSP32/HO-1 mRNA levels relative to control utricles. More modest upregulation of HSP90 and HSP27 mRNA were observed with celastrol. Error bars represent S.E.M. on real-time qRT-PCRs performed in triplicate. (b) Western blot analysis of celastrol-mediated HSP induction. Utricles treated with a $43^{\circ} \mathrm{C}$ heat shock were used for comparison. Celastrol induced HSP70 expression levels that were comparable to those induced by heat shock. Celastrol-mediated HSP32 induction was greater than that induced by heat shock. (c and g) Celastrol inhibits aminoglycosideinduced hair cell death. (c) Control utricles display normal hair cell densities. (d) Celastrol does not decrease hair cell viability. (e) Neomycin results in a significant loss of hair cells. (f) Celastrol inhibits neomycin-induced hair cell death. (g) Celastrol inhibits neomycin-induced hair cell death across the dose-response relationship (2-way ANOVA $\left.F_{1,132}=28.916, P<0.001\right)$. (h) Celastrol inhibits aminoglycoside-induced JNK activation. JNK activation was analyzed by phosphorylation status. Celastrol (1.5 $\mu \mathrm{M}$ for $3 \mathrm{~h}$ ) does not result in JNK activation. Neomycin resulted in robust JNK activation relative to basal levels. Neomycin-induced JNK activation is inhibited by celastrol. Scale bar in $\mathbf{f}=20 \mu \mathrm{M}$. Asterisks in $\mathbf{g}$ denote a significant difference in neomycin-induced hair cell death between celastrol-treated and untreated utricles by post hoc tests

in $\mathrm{Hsf}_{-1} \mathrm{1}^{-1-}$ utricles. Thus, although $\mathrm{Hsf}-1$ is required for celastrol-mediated induction of HSP70, it is not required for induction of HSP32/HO-1.

Celastrol induces Nrf2 expression and transcriptional activation of Nrf2 downstream target genes. Celastrol can induce expression of cytoprotective antioxidant genes via activation of the transcription factor Nrf-2 (NF-E2-related factor-2). ${ }^{22}$ In order to determine whether celastrol induces Nrf2 activation in utricles, explants were incubated in celastrol and examined for Nrf-2 mRNA levels (Figure 3a).
Celastrol resulted in $\sim 3$-fold increase in Nrf2 mRNA expression. Immunocytochemistry was used to examine Nrf2 expression and cellular localization after celastrol treatment (Figures $3 \mathrm{~b}-\mathrm{g}$ ). In control utricles, Nrf2 was located primarily in the cytoplasm (Figures $3 \mathrm{c}$ and $\mathrm{d}$ ). Treatment with celastrol resulted in an increase in total cellular Nrf2 immunoreactivity as well as an increase in nuclear Nrf2, suggesting translocation of Nrf2 to the nuclei of hair cells (Figures $3 f$ and $g$ ). In order to further examine celastrol-mediated Nrf2 activation, we analyzed expression levels of four other Nrf2 target genes after treatment with 

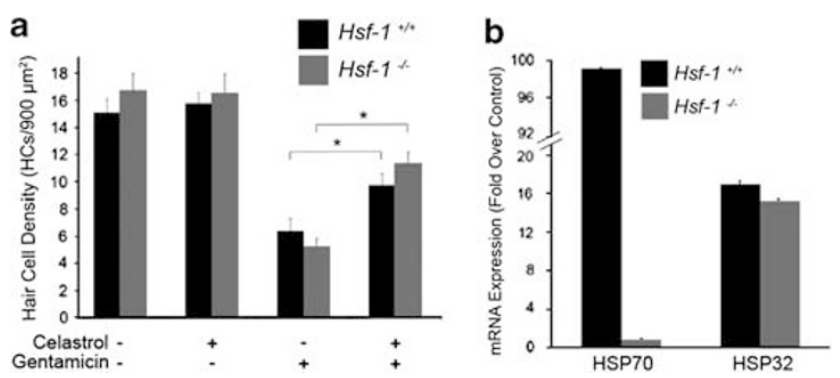

Figure $2 \mathrm{Hsf}-1$ is not required for celastrol-mediated protection or $\mathrm{HSP} 32 / \mathrm{HO}-1$ induction. (a) Utricles from $\mathrm{Hsf-1}{ }^{+/+}$and $\mathrm{Hsf-}-^{-/-}$mice were treated with celastrol $(1.5 \mu \mathrm{M}$ for $3 \mathrm{~h}$ ) and/or gentamicin ( $5 \mathrm{mM}$ for $24 \mathrm{~h}$ ). Celastrol did not result in loss of hair cells in utricles from either $\mathrm{Hsf-1^{+/+ }}$ or ${\mathrm{Hsf}-1^{-/}}^{-}$mice. Gentamicin resulted significant hair cell loss in utricles of both genotypes. Celastrol inhibited gentamicininduced hair cell death in both $\mathrm{Hsf}_{-1} \mathrm{1}^{++}$and $\mathrm{Hsf}_{-} \mathrm{1}^{-/}$utricles (3-way ANOVA $\left.F_{1,59}=34.24, P<0.001\right)$. (b) Celastrol induces HSP32/HO-1 expression in the absence of $\mathrm{Hsf}-1$. Utricles from $\mathrm{Hsf}_{-1}{ }^{-1-}$ mice and their wild-type littermates were incubated in celastrol for $3 \mathrm{~h}$ before RNA extraction. Celastrol resulted in $\sim 100$-fold increase in HSP70 mRNA expression in utricles from $\mathrm{Hsf}_{-1} 1^{+/+}$mice, but it did not result in increased HSP70 mRNA in utricles from $\mathrm{Hsf}_{-1}{ }^{-/}$mice. In contrast, celastrol treatment resulted in similar increases in HSP32/HO-1 mRNA levels in utricles of both $\mathrm{Hsf}-1^{+/+}$and $\mathrm{Hsf-1^{-1- }}$ mice. Error bars represent S.E.M. on realtime qRT-PCRs performed in triplicate

celastrol. Nrf2 transcriptionally activates a number of antioxidant genes, including $\mathrm{HSP} 32 / \mathrm{HO}-1$, glutathione S-transferase mu 1 (Gstm1), NAD(P)H:quinone oxidoreductase 1 (NQO1), UDP-glucuronosyltransferase (UGT), and gammaglutamate cysteine ligase catalytic subunit (GCLC) ${ }^{23} \mathrm{mRNA}$ levels of Nrf2 target genes were analyzed in control and celastrol-treated utricles by quantitative real-time RT-PCR (Figure 3h). mRNA levels of all four Nrf2 target genes increased in response to celastrol treatment. These data provide additional evidence that celastrol activates Nrf2, and they suggest that celastrol induction of $\mathrm{HSP} 32 / \mathrm{HO}-1$ in the absence of Hsf-1 may occur through activation of Nrf-2.

HSP32/HO-1 is required for the protective effect of celastrol. We next investigated the role of HSP32/HO-1 in celastrol's protective effect against aminoglycoside-induced hair cell death by using an $\mathrm{HSP} 32 / \mathrm{HO}-1$ inhibitor, zinc protoporphyrin IX (ZnPPIX). In order to account for protection conferred by celastrol-induced HSP70, this experiment was performed using utricles from both wild-type $\left(\mathrm{HSP}^{+/+}\right)$ and HSP70 knockout $\left(\mathrm{HSP}^{-1-}\right)$ mice. Utricles from mice of both genotypes were cultured in (1) control media, (2) celastrol plus ZnPPIX, (3) gentamicin, (4) celastrol plus gentamicin, or (5) celastrol plus gentamicin and ZnPPIX (Figure 4a). Culturing utricles in celastrol plus ZnPPIX did not reduce hair cell viability. Utricles exposed to gentamicin had significant hair cell loss. Celastrol significantly inhibited gentamicin-induced hair cell death in utricles of both genotypes. The HSP32/HO-1 inhibitor ZnPPIX abolished celastrol's protective effect against aminoglycoside-induced hair cell death in both $\mathrm{HSP} 7 \mathrm{O}^{+/+}$and $\mathrm{HSP}^{-1-}$ utricles (1-way ANOVA $F_{1,29}=26.35, \quad P<0.0001$ ). These data indicate that the protective effect of celastrol does not require $\mathrm{HSP} 70$, but it does require $\mathrm{HSP} 32 / \mathrm{HO}-1$.
HSP32/HO-1 inhibits both aminoglycoside-induced hair cell death and JNK activation. Next we used the HSP32/ $\mathrm{HO}-1$ inducer cobalt protoporphyrin IX (CoPPIX) to examine whether $\mathrm{HSP} 32 / \mathrm{HO}-1$ induction alone is protective. Utricles were treated with CoPPIX for $12 \mathrm{~h}$ before exposure to neomycin for $24 \mathrm{~h}$ (Figure 4b). Neomycin resulted in significant hair cell death, which was inhibited by CoPPIX (2-way ANOVA $F_{1,9}=10.36, P<0.011$ ).

Our data indicate that both heat shock (data not shown) and celastrol inhibit aminoglycoside-induced JNK activation. CoPPIX was used to determine whether HSP32/HO-1 alone can inhibit JNK activation. Utricles were incubated in CoPPIX $(20 \mu \mathrm{M})$ for $12 \mathrm{~h}$ and then treated with neomycin (Figure $4 \mathrm{c}$ ). Control and CoPPIX-treated utricles displayed little JNK activation (Figure 4c, lanes 1 and 2). Neomycin resulted in a robust increase in JNK phosphorylation (Figure 4c, lane 3), which was inhibited by CoPPIX (Figure 4c, lane 4). These data indicate that HSP32/HO-1 alone inhibits pro-apoptotic JNK signaling in aminoglycoside-treated hair cells. Taken together with the previous experiments, these data indicate that $\mathrm{HSP} 32 / \mathrm{HO}-1$ is the major mediator of celastrol-induced protection.

CO inhibits aminoglycoside-induced hair cell death. HSP32/HO-1 catalysis of heme results in the production of $\mathrm{CO}$, which is cytoprotective in a variety of systems. ${ }^{24} \mathrm{We}$ utilized the $\mathrm{CO}$ donor tricarbonyldichlororuthenium (II) dimer (CORM2) to further investigate the mechanisms underlying HSP32/HO-1-mediated protection. Utricles were cultured in neomycin and CORM2 (Figure 4d). CORM2 provided significant protection against neomycin-induced hair cell death (1-way ANOVA $F_{1,25}=79.29, \quad P<0.0001$ ), suggesting that the protective effect of celastrol-induced HSP32/HO-1 expression may be mediated (at least in part) by $\mathrm{HSP} 32 / \mathrm{HO}-1$-induced $\mathrm{CO}$ production.

Celastrol inhibits aminoglycoside-induced hearing loss in vivo. Our overall goal is to develop a clinical co-therapy to inhibit aminoglycoside-induced hearing loss in humans. Therefore, we next examined celastrol's effect on hearing loss caused by systemic aminoglycoside exposure in adult mice. Hearing thresholds were measured using auditory brainstem response (ABR) recordings before and after aminoglycoside treatment. Threshold shifts are reported as the difference between pretreatment thresholds and posttreatment thresholds. Thresholds were analyzed for several frequencies across the normal range of hearing sensitivity in mice. Mice received either: (1) Celastrol vehicle (cremophor/ PBS, see Materials and Methods for details) and kanamycin vehicle (saline), (2) Celastrol (plus saline), (3) kanamycin (plus celastrol vehicle), or (4) Celastrol and kanamycin (Figure 5, top panel). Mice receiving kanamycin alone had significant hearing loss at all frequencies tested, with mean threshold shifts ranging from $28 \mathrm{~dB}$ (at $4 \mathrm{kHz}$ ) to $63 \mathrm{~dB}$ (at $32 \mathrm{kHz}$ ). Celastrol significantly reduced kanamycininduced hearing loss (RM-ANOVA, $F_{3,12}=104.77$, $P<0.0001, n=16)$.

Celastrol inhibits aminoglycoside-induced cochlear hair cell death in vivo. In order to determine whether celastrol 


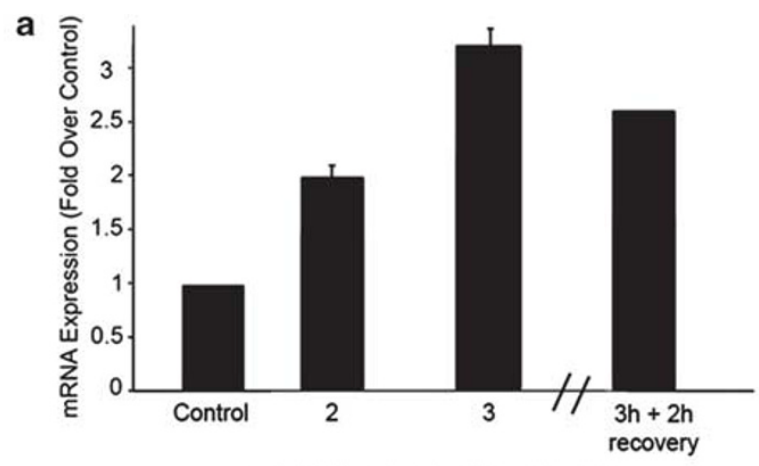

Celastrol Exposure Time (Hours)
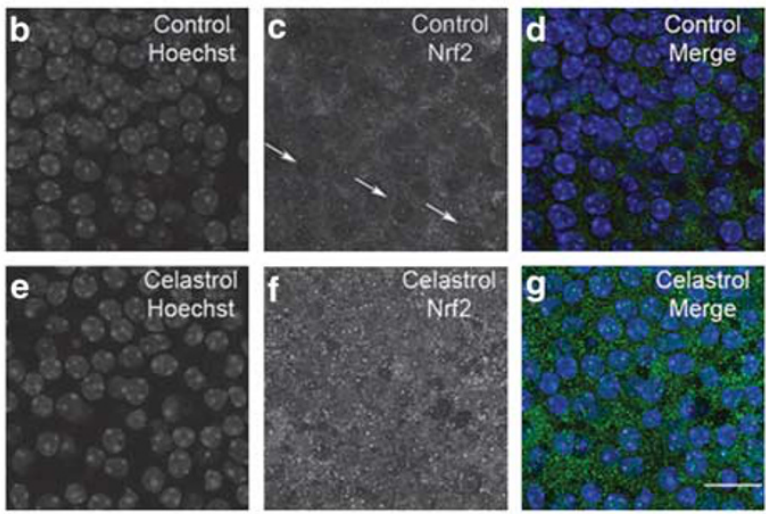

h

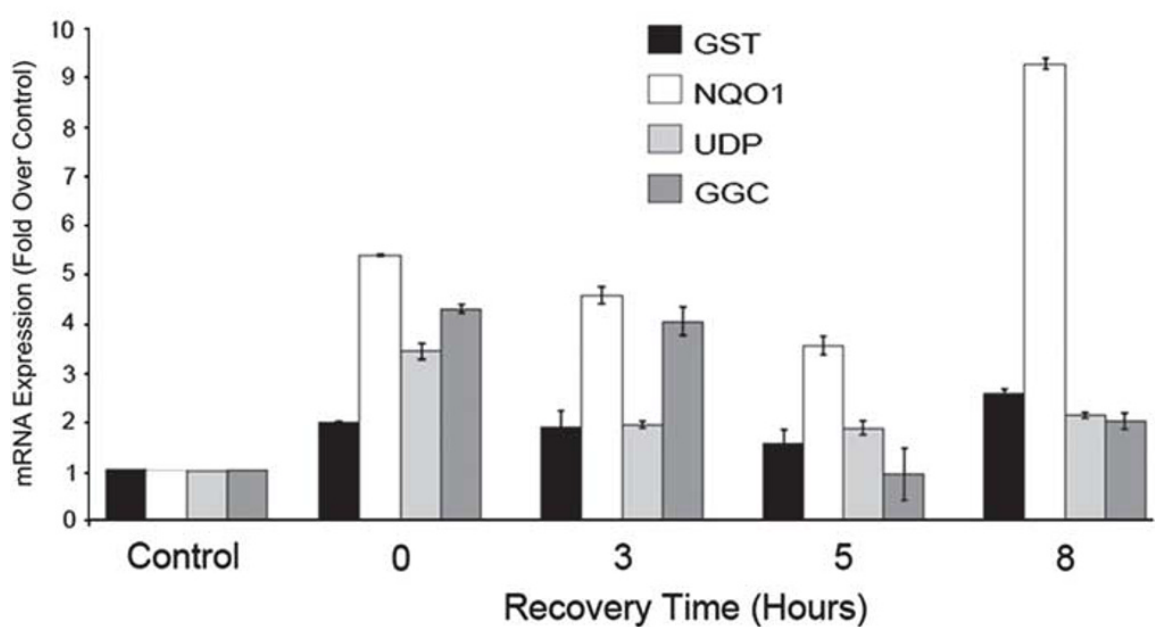

Figure 3 Celastrol induces Nrf2 activation. (a) RT-PCR analysis of Nrf2 mRNA levels in response to celastrol. Nrf2 mRNA expression peaked after $3 \mathrm{~h}$ of celastrol incubation and declined thereafter. Error bars represent S.E.M. on real-time qRT-PCRs performed in triplicate. $(\mathbf{b}-\mathbf{g}) \mathrm{Nrf2}$ immunolocalization. Hair cell nuclei were labeled with Hoescht. (b-d) In control utricles Nrf2 is localized to the hair cell cytosol, and the nuclei appear as dark voids (arrows in $\mathbf{c}$ ). (e-g) Celastrol results in increased Nrf2 immunoreactivity as well as Nrf2 translocation to the nucleus. Scale bar in $\mathbf{g}=20 \mu \mathrm{M}$. (h) qRT-PCR analysis of Nrf2 transcriptional targets. GST, NQO1, UDP, and GGC expression were all increased in celastrol-treated utricles relative to control levels. Error bars represent S.E.M. on real-time qRT-PCRs performed in triplicate

inhibits cochlear hair cell death caused by systemic aminoglycoside exposure, cochleas were harvested from mice after ABR post-testing. Cochleas were dissected into apical, middle, and basal half-turns. Cochlear hair cells were labeled using an antibody against Myosin VIla. A reference mouse cochlea is shown to demonstrate the normal cochlear architecture of three rows of outer hair cells and a single row of inner hair cells (Figure 5, lower panel). Aminoglycoside damage resulted in a stereotypical gradient of cochlear hair cell death in which hair cells in the basal turn are more susceptible to death than hair cells in the apical turn, and outer hair cells are more susceptible than inner hair cells. Outer hair cell loss was extensive in all three cochlear turns of kanamycin-treated mice (Figures $5 a-c$ ). The middle and 

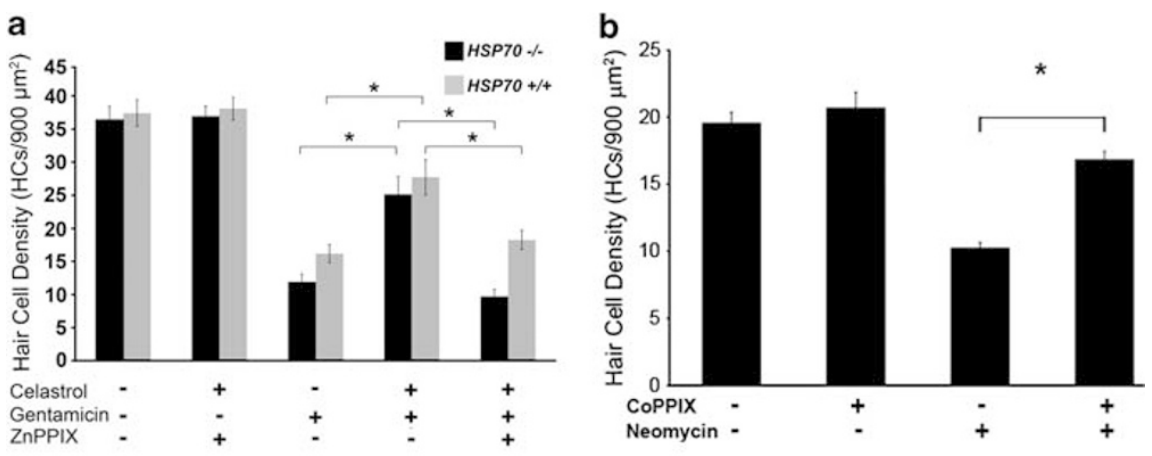

C

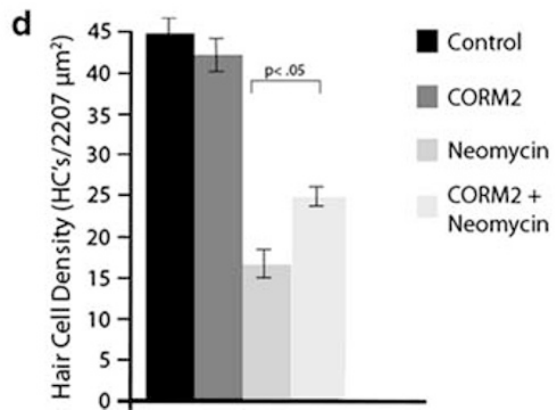

Figure $4 \mathrm{HSP} 32 / \mathrm{HO}-1$ is the major mediator of celastrol's protective effect. (a) HSP32/HO-1 is required for the protective effect of celastrol. Utricles from both $\mathrm{HSP}^{-1-}$ and $\mathrm{HSP}^{+/+}$mice were treated with celastrol and the HSP32/HO-1 inhibitor ZnPPIX. Gentamicin resulted in significant hair cell death in utricles of both genotypes. Celastrol inhibited gentamicin-induced hair cell death in both $\mathrm{HSP}^{-/-}$and $\mathrm{HSP}^{+/+}$utricles. ZnPPIX abolished the protective effect of celastrol in both $\mathrm{HSP}^{-1-}$ and $\mathrm{HSP}^{+/ /+}$utricles (1-way ANOVA $\left.F_{1,29}=26.35, P<0.0001\right)$. Asterisks indicate significance $(P<0.05)$ by post hoc analysis. (b) HSP32/HO-1 inhibits aminoglycosideinduced hair cell death. Utricles were treated with the HSP32/HO-1 inducer CoPPIX. HSP32/HO-1 induction inhibited aminoglycoside-induced hair cell death (2-way ANOVA $F_{1,9}=10.36, P<0.011$ ). (c) HSP32/HO-1 inhibits aminoglycoside-induced JNK activation. Neomycin increased JNK activation, and this activation was inhibited by CoPPIX. (d) $\mathrm{CO}$ inhibits aminoglycoside-induced hair cell death. Utricles were treated with CORM2, a CO-releasing molecule. CORM2 partially inhibited neomycin-induced hair cell death (1-way ANOVA $\left.F_{1,25}=79.29, P<0.0001\right)$

basal cochlear turns of kanamycin-treated mice showed complete loss of outer hair cells, while the inner hair cells remained largely intact (Figures $5 b$ and $c$ ). Celastrol protected outer hair cells in the middle and apical cochlear turns (Figures $5 d$ and $e$ ), but it was not protective in the basal turn (Figure 5f). These data indicate that celastrol protects against aminoglycoside-induced cochlear hair cell death in vivo.

\section{Discussion}

We previously showed that HSP induction has a significant protective effect against aminoglycoside-induced hair cell death. ${ }^{13-15}$ Here we have examined the protective effect of celastrol, a pharmacological inducer of HSPs and antioxidant genes, against aminoglycoside-induced hair cell death and hearing loss. Celastrol induced HSP70 and HSP32/HO-1, and it inhibited aminoglycoside-induced hair cell death in utricles. Moreover, celastrol inhibited aminoglycoside ototoxicity in mice receiving systemic kanamycin treatment. HSP32/HO-1 is both necessary and sufficient for celastrolmediated protection.

Celastrol induces HSP32/HO-1 independently of Hsf-1. Celastrol induces Hsf-1 DNA binding and hyperphosphorylation, resulting in HSP expression. ${ }^{19}$ The HSP32/HO-1 gene promoter contains a functional Hsf-1- binding site that results in transcriptional activation in response to heat shock. ${ }^{25}$ Our mRNA and protein expression analyses indicate that celastrol induces HSP32/ $\mathrm{HO}-1$ and HSP70 expression in utricles. The mechanisms by which celastrol induces HSP expression remain unclear, however, gene and protein expression analyses indicate that celastrol functions as an HSP90 inhibitor. ${ }^{26}$ HSP90 inhibitors are well-known inducers of HSP expression through derepression of Hsf-1 transcriptional activity. ${ }^{19,22}$ However, our data indicate that Hsf-1 is not required for celastrolmediated protection against aminoglycoside-induced hair cell death. In the absence of Hsf-1, celastrol still induced HSP32/ $\mathrm{HO}-1$ and inhibited hair cell death. This finding is consistent with a recent report that $\mathrm{HSP} 32 / \mathrm{HO}-1$ was still induced by heat shock in the presence of an Hsf-1 inhibitor in cardiac myocytes. $^{27}$

Our data suggest that Hsf-1-independent induction of HSP32/HO-1 may be mediated by Nrf2, another transcription factor that can transactivate $\mathrm{HSP} 32 / \mathrm{HO}-1$ expression. ${ }^{22}$ Under normal conditions Nrf2 is negatively bound by Keap1 in the cytosol, where it is targeted for ubiquitination and proteosomal degradation. When exposed to an oxidant or cellular stress, modifications in Keap 1 disrupt Nrf2 ubiquitination, resulting in increased Nrf2 protein levels and translocation to the nucleus. ${ }^{28}$ Our data indicate that celastrol increases Nrf2 immunoreactivity and induces Nrf2 translocation to the nucleus, suggesting activation of Nrf2 transcriptional activity. 

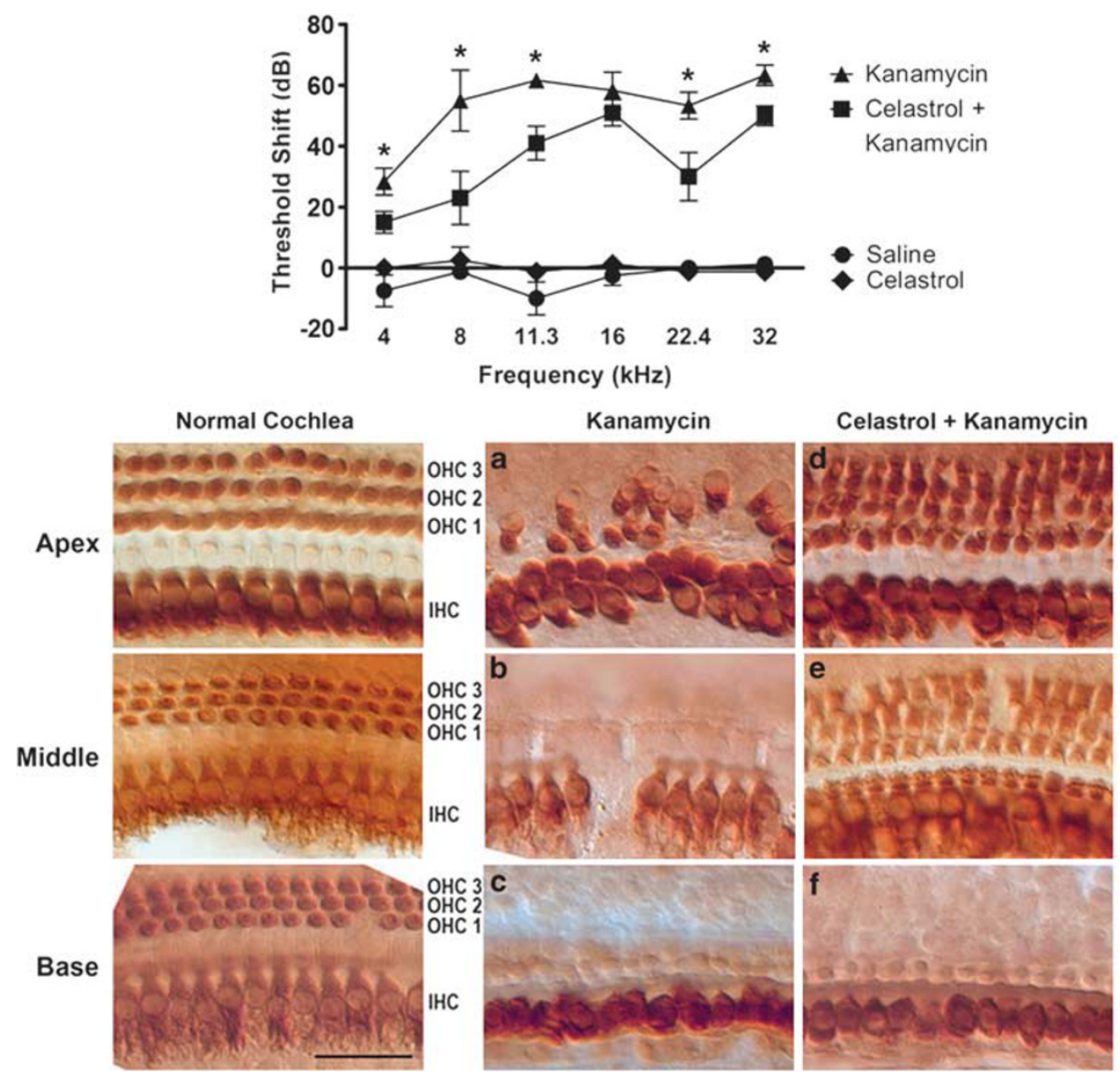

Figure 5 Celastrol inhibits aminoglycoside-induced hearing loss and hair cell death in vivo. Top panel: hearing testing via ABR analysis was used to determine whether celastrol inhibits aminoglycoside-induced hearing loss in vivo. Pre-test ABR thresholds were determined, then mice received daily injections of celastrol and/or kanamycin for 14 days. ABR hearing thresholds were again measured 3 weeks after the final injections, and data are reported as threshold shifts (that is, the difference between pre-test and post-test thresholds). Mice treated with kanamycin showed significant hearing losses (threshold shifts) at all frequencies tested. Mice treated with celastrol plus kanamycin had significantly smaller threshold shifts than mice given kanamycin alone (RM-ANOVA, $\left.F_{3,12}=104.77, P<0.0001, n=16\right)$. Asterisks indicate significance $(P<0.05)$ by post hoc analysis. Lower panel: celastrol inhibits aminoglycoside-induced cochlear hair cell death in vivo. Myosin Vlla immunohistochemistry was used to label hair cells in cochleas of mice treated with kanamycin and celastrol. The normal mouse cochlea (shown for reference) contains a single row of inner hair cells (IHC) and three rows of outer hair cells $(\mathrm{OHC} 1-3)$. (a-c) The cochlea of a mouse treated with kanamycin shows some loss of outer hair cells in the apex (a) and total loss of outer hair cells in the middle (b) and base (c). Occasional loss of inner hair cells is also evident (b). ( $\mathbf{d}$ and $\mathbf{e}$ ) The cochlea of a mouse treated with kanamycin plus celastrol retains of the majority of outer hair cells in the apical and middle turns, and all inner hair cells are present. (f) Celastrol did not protect outer hair cells in the basal turn of the cochlea. Scale bar $=30 \mu \mathrm{m}$

Moreover, celastrol induced mRNA expression of other Nrf2 target genes. Thus, celastrol-mediated HSP32/HO-1 induction may be via Nrf2 activation.

HSP32/HO-1 is the major mediator of the protective effect of celastrol. As celastrol is a potent inducer of $\mathrm{HSP} 32 / \mathrm{HO}-1$, we examined whether $\mathrm{HSP} 32 / \mathrm{HO}-1$ is required for the protective effect of celastrol. ZnPPIX is a small molecule inhibitor of HSP32/HO-1 activity. ${ }^{29} \mathrm{ZnPPIX}$ abolished celastrol's protective effect against aminoglycoside-induced hair cell death, indicating that HSP32/HO-1 is required for celastrol-induced cytoprotection. The specific mechanisms by which HSP32/HO-1 confers protection are unclear. Our data using the CO donor CORM2 indicate that $\mathrm{CO}$ inhibits aminoglycoside-induced hair cell death, suggesting that HSP32/HO-1-mediated $\mathrm{CO}$ production may have a role in celastrol's protective effect. CO has important roles in intracellular signaling, and it can protect against mitochondrial dysfunction and oxidative stress. $^{30} \mathrm{CO}$ interacts with Complex IV of the electron transport chain, inducing a backup of electrons at Complex III, resulting in low levels of superoxide production. This low-level ROS production is thought to act as a preconditioning stress for further insults. ${ }^{31}$

Mechanisms of celastrol-mediated protection. Our data suggest that the protective effect of celastrol occurs via HSP32-mediated inhibition of JNK activation. The importance of JNK as a mediator of aminoglycosideinduced hair cell death has been established by several studies showing that inhibition of JNK is sufficient to inhibit aminoglycoside-induced hair cell death and hearing loss. ${ }^{7,10}$ The mechanisms by which aminoglycosides activate JNK 


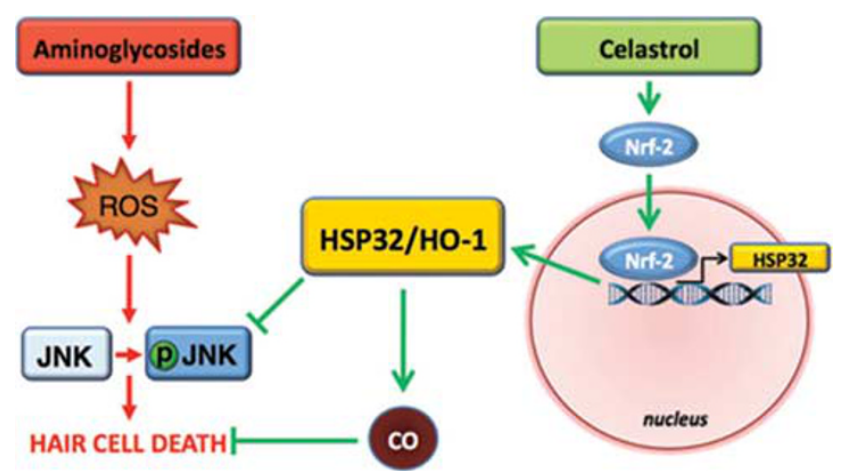

Figure 6 Potential mechanisms of celastrol-mediated protection against aminoglycoside-induced hair cell death. Aminoglycoside antibiotics result in increased ROS production and pro-apoptotic JNK activation in hair cells. Celastrol activates the Nrf2-transcription factor and induces HSP32/HO-1. HSP32/HO-1 inhibits pro-apoptotic JNK activation and hair cell death, possibly through the action of $\mathrm{CO}$

signaling in hair cells are unclear. However, it is well established that aminoglycoside exposure results in generation of ROS in hair cells, ${ }^{6}$ and data from other systems indicate that ROS are activators of $\mathrm{JNK}^{32}$

Both heat shock and celastrol resulted in induction of HSP70 and HSP32/HO-1. In addition, both heat shock (data not shown) and celastrol inhibited aminoglycoside-induced JNK phosphorylation. HSP70 is a potent inhibitor of JNK phosphorylation. ${ }^{33}$ Therefore, in wild-type mice, HSP70 may have a role in the protective effect of celastrol against aminoglycoside-induced ototoxicity via inhibition of JNK phosphorylation. However, HSP70 is not required for the protective effect of celastrol, as celastrol was protective in utricles from both $\mathrm{HSP}^{-1-}$ and $\mathrm{Hsf}_{-1}^{-1-}$ mice.

Our data suggest that HSP32/HO-1 is both necessary and sufficient for celastrol-mediated protection. Inhibition of HSP32/HO-1 using ZnPPIX abolished the protective effect of celastrol. Moreover, induction of HSP32/HO-1 using CoPPIX inhibited aminoglycoside-induced JNK activation and hair cell death. HSP32/HO-1 is associated with increased antioxidant activity and ROS scavenging via its downstream products bilirubin and $\mathrm{CO} .{ }^{30}$ Our data using CORM2 indicate that $\mathrm{CO}$ is protective against aminoglycoside-induced hair cell death. Therefore, HSP32/HO-1-mediated CO production may inhibit ROS formation upstream of JNK activation in hair cells. Taken together, our data are consistent with a model in which the protective effect of celastrol occurs via Nrf-2-mediated induction of HSP32/HO-1. HSP32/HO-1 inhibits JNK activation, possibly via its generation of $\mathrm{CO}$, which is itself protective (Figure 6).

Towards development of a co-therapy to prevent ototoxic drug-induced hearing loss. Mice treated with celastrol had significantly less hearing loss and more hair cell survival compared with those treated with kanamycin alone, suggesting that celastrol may hold potential as a co-therapy aimed at preventing aminoglycoside-induced hearing loss in humans. Celastrol is one of several pharmacologically active compounds in extracts of $T$. wilfordii, also known as Thunder of God Vine (lei gong teng in China). Extracts of this vine have been used for many years in traditional Chinese medicine. ${ }^{20}$ Although purified celastrol itself has not yet been studied in clinical trials, there have been several studies showing the safety and efficacy of extracts of $T$. wilfordii. Ethyl acetate extracts of $T$. wilfordii were entered into phase I trials in $2001 .^{34}$ Doses up to $570 \mathrm{mg} /$ day of extract were well-tolerated, and doses of $360 \mathrm{mg} /$ day were associated with clinical improvement of the symptoms of rheumatoid arthritis. ${ }^{34}$ In another trial, rheumatoid arthritis patients receiving extracts of $T$. wilfordii showed greater improvement in symptoms and reduction in inflammatory interleukin-6 levels than those receiving sulfasalazine. ${ }^{35} T$. wilfordii extract also inhibits transplant rejection and renal dysfunction in kidney transplant patients. ${ }^{36}$ Although additional clinical data are necessary to assess the safety and efficacy of celastrol, these initial studies suggest that celastrol may be welltolerated and effective in humans.

Similar to aminoglycosides, cisplatin is a highly efficacious drug with significant ototoxic side effects. Cisplatin is an anticancer drug that is widely used to treat a variety of solid tumors. Induction of HSP32/HO-1 and the products of heme catalysis, $\mathrm{CO}$ and bilirubin protect auditory cells from cisplatininduced apoptosis. ${ }^{16}$ Our unpublished data indicate that celastrol also attenuates hair cell death caused by a moderate dose of cisplatin. These data suggest that celastrol may also hold promise as a co-therapy for the inhibition of hearing loss caused by cisplatin.

In summary, our data indicate that celastrol holds potential as a clinical co-therapy aimed at preventing aminoglycosideinduced ototoxicity. Celastrol activates both HSP32/HO-1 and $\mathrm{HSP} 70$. HSP32/HO-1 is the primary mediator of celastrol's protective effect.

\section{Materials and Methods}

Model system. Our studies utilize whole-organ cultures of utricles from adult mice. The utricle is a vestibular organ, and the hair cells of the utricle are similar in both structure and function to the hair cells in the organ of Corti. Adult mammalian cochlear hair cells do not survive well in vitro using current culture techniques, and the hair cells of the mouse utricle are sensitive to death from exposure to the same therapeutic drugs that kill cochlear hair cells. ${ }^{7,37}$ In addition, the cellular mechanisms underlying ototoxic hair cell death and survival are similar for both utricular and cochlear hair cells. ${ }^{2,3,15,38}$ The utricle model system is currently the bestcharacterized in vitro preparation for studies of adult mammalian hair cells. ${ }^{37}$

Animals. All mice were euthanized by either overdose of Nembutal (Abbot Laboratories, North Chicago, IL, USA) or $\mathrm{CO}_{2}$ inhalation followed by decapitation. Utricles were dissected as previously described. ${ }^{37}$ Animals were housed in the central animal care facility at the Medical University of South Carolina, and all experimental procedures and protocols were approved by the MUSC Institutional Animal Care and Use Committee.

CBA/J Mice. Adult CBA/J mice (4-6 weeks of age) were purchased from Harlan (Indianapolis, IN, USA) and housed in the MUSC animal care facility.

Hsf-1 ${ }^{-1-}$ mice. $H s f-1^{-/}$mice were the gift of Dr. Margaret Lomax, who backcrossed the original $\mathrm{Hsf}-\mathrm{1}^{-/}$mice (on the mixed genetic background $\mathrm{C}, 129 \mathrm{X} 1$ $\left(129 \mathrm{X} 1 / \mathrm{SvJ} \times \mathrm{BALB} / \mathrm{c}^{39}\right)$ onto the CBA/CaJ (The Jackson Laboratory, Bar Harbor, ME, USA) background for at least four generations. At MUSC, the mice were backcrossed for additional 4-5 generations. Hsf-1 ${ }^{-/}$mice were generated by replacing a 1.8-kb genomic fragment with a 2-kb NEO insert using a gene targeting vector for Hsf-1. ${ }^{39}$ Litters were obtained from heterozygote breeding. Mice were genotyped 21 days after birth. Tail clips $(1 \mathrm{~mm})$ were lysed using DirectPCR Lysis 
Reagent (Viagen Biotech 101-T, Los Angeles, CA, USA). Crude DNA from tail lysates was used in one-step PCR genotyping (TaqMan Core Reagent Kit, Applied Biosystems N808-0228, Foster City, CA, USA; Mastercycler, Eppendorf 5333, Hamburg, Germany). Primers were as follows: Forward Hsf-1 primer $5^{\prime}-\mathrm{A}$ GACCTGTCCTGTGTGCCTAGC-3', reverse Hsf-1 primer 5'-CAGTTCA ACTGCCTACACAGACC- $3^{\prime}$, yielding a 562-bp product of the Hsf-1 gene; forward NEO primer $5^{\prime}$-AAGTATCCATCATGGCTGATGC-3', reverse NEO primer $5^{\prime}$-TAGCCAACGCTATGTCCTGATA-3' ${ }^{\prime}$, yielding a 339 -bp product of the inserted NEO gene.

HSP70.1/3 ${ }^{-1-}$ mice. HSP70.1/3 ${ }^{-/-}$mice were obtained from the Mutant Mouse Regional Resource Center at the University of California, Davis. HSP70. $1 / 3^{-/-}$mice have a targeted deletion of both HSP70.1 and HSP70.3. ${ }^{40}$ Both genes are on mouse chromosome 17 separated by $11 \mathrm{~kb}$ of genomic DNA. This fragment has been replaced by a 3.1-kb neo gene, driven by the RNA polymerase I promoter. These mice are on a mixed C57BL/6 $\times 129 \mathrm{SvJ}$ background, and homozygote knockouts are viable and fertile. Thus, litters were obtained through homozygote breeding. Wild-type B6/129SF2 mice were purchased from the Jackson Laboratory and used as strain controls.

Utricle cultures. Utricles from adult mice were dissected under sterile conditions and cultured free-floating (4-6 utricles/well) in 24-well tissue culture plates as previously described. ${ }^{37}$ Culture medium consisted of Basal Medium Eagle (Sigma, St. Louis, MO, USA) supplemented with Earle's Balanced Salt Solution (Invitrogen, Carlsbad, CA, USA) (2:1 v/v), 5\% fetal bovine serum (Invitrogen) and $50 \mathrm{U} / \mathrm{ml}$ penicillin $\mathrm{G}$ (Sigma). Utricles pretreated with celastrol (Calbiochem, San Diego, CA, USA) were incubated in $1.5 \mu \mathrm{M}$ celastrol in culture medium for $3 \mathrm{~h}$ and allowed to recover in culture medium for $5 \mathrm{~h}$. Following recovery, CBA/J utricles were exposed to varying concentrations of neomycin (1-5 mM) (Sigma) in culture medium in an incubator at $37^{\circ} \mathrm{C}$ and $5 \% \mathrm{CO}_{2}$ for $24 \mathrm{~h}$. Neomycin is not toxic to hair cells from $\mathrm{Hsf}_{-1}^{-1}$ and $\mathrm{HSP} 70.1 / 3^{--}$mice because these knockout strains contain a neomycin resistance gene (Neo), which has been inserted into the target gene locus. ${ }^{39,40}$ The Neo gene encodes an aminoglycoside kinase class-II enzyme (APH $\left(3^{\prime}\right)-$ II), which modifies neomycin, kanamycin, and other aminoglycosides at the $3^{\prime}$-hydroxyl group. Gentamicin lacks this functional group and therefore is not a substrate for APH $\left(3^{\prime}\right)-11 .^{41}$ Utricles from $H s f-1^{-/-}$and $H S P 70.1 / 3^{-/-}$mice were pretreated with celastrol for $3 \mathrm{~h}$ and allowed to recover for $5 \mathrm{~h}$ before being exposed to $5 \mathrm{mM}$ gentamicin sulfate (Sigma) in culture medium, for $24 \mathrm{~h}$ at $37^{\circ} \mathrm{C}$ and $5 \% \mathrm{CO}_{2}$.

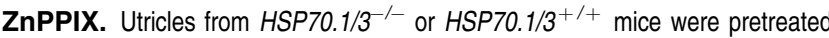
with celastrol for $3 \mathrm{~h}$ and allowed to recover for $5 \mathrm{~h}$ before being exposed to $5 \mathrm{mM}$ gentamicin sulfate (Sigma) in culture medium, for $24 \mathrm{~h}$ at $37^{\circ} \mathrm{C}$ and $5 \% \mathrm{CO}_{2}$. Some utricles were maintained in the HSP32 inhibitor ZnPPIX $(10 \mu \mathrm{M})$ (Frontier Scientific, Logan, UT, USA) for the entire culture period.

CoPPIX. Utricles from CBA/J mice were pretreated with the HSP32/HO-1 inducer CoPPIX $(20 \mu \mathrm{M})$ (Frontier Scientific) for $12 \mathrm{~h}$ before being exposed to $2 \mathrm{mM}$ neomycin in culture medium for $12 \mathrm{~h}$ at $37^{\circ} \mathrm{C}$ and $5 \% \mathrm{CO}_{2}$.

Tricarbonyldichlororuthenium (II) dimer. Utricles from $\mathrm{CBA} / \mathrm{J}$ mice were co-cultured with the $\mathrm{CO}$ donor tricarbonydichlororuthenium (II) dimer $(50 \mu \mathrm{M})$ (Sigma) and $2 \mathrm{mM}$ neomycin sulfate in culture medium for $24 \mathrm{~h}$ at $37^{\circ} \mathrm{C}$ and $5 \% \mathrm{CO}_{2}$
Western blot analyses. Utricles (8-10 per condition) were homogenized in RIPA cell lysis buffer ( $150 \mathrm{mM} \mathrm{NaCl}, 1 \mathrm{mM}$ ethylenediaminetetraacetic acid (EDTA), $1 \%$ NP-40, $0.25 \%$. Na deoxycholate, $0.1 \%$ SDS, and $1 \mathrm{mM} \mathrm{NaVO}_{4}$ in PBS) supplemented with Protease Inhibitor Cocktail Set III $10 \mathrm{mM}$ (Calbiochem). Protein lysates were subjected to SDS-PAGE using 4-15\% Tris- $\mathrm{HCl}$ gels (Bio-Rad, Hercules, CA, USA), then transferred onto PVDF membranes (Millipore, Billerica, MA, USA). Primary antibodies for HSP90, HSP70, HSP32 and HSP27 (Cell Signaling, Danvers, MA, USA; $1: 1000$ ), and secondary antibodies, Immun-Star Goat Anti-Mouse-HRP Conjugate (\#170-5047, Bio-Rad 1:2000) and Immun-Star Goat Anti-Rabbit-HRP Conjugate (\#170-5046, Bio-Rad 1:2000), were diluted in blocking solution, consisting of $5 \%$ milk (Bio-Rad). PVDF membranes were incubated in primary antibodies overnight at $4{ }^{\circ} \mathrm{C}$ and secondary antibodies for $1-2 \mathrm{~h}$ at room temperature. Signal amplification and visualization were achieved using chemiluminescence (SuperSignal West Dura Extended Duration Substrate) using pre-flashed CL-XPosure Film (Pierce Biotechnology, Rockford, IL, USA). Each experiment was repeated 2-4 times with similar results, and a representative blot is shown.

JNK assays. JNK1 and JNK2/3 phosphorylation were analyzed by western blot using a phosphorylation-state specific JNK antibody (\# 9255S, Cell Signaling) that specifically recognizes threonine ${ }^{183}$ and tyrosine ${ }^{185}$-phosphorylated JNK1 and JNK2/3. After blotting, blots were stripped using Re-Blot Plus Strong Antibody Stripping Solution (Millipore) and re-probed with a total JNK antibody, which recognizes equally well the phosphorylated and non-phosphorylated forms of JNK (\#9258, Cell Signaling). There are three JNK genes (JNK1, JNK2, JNK3), each of which undergoes alternative splicing to yield multiple isoforms. Each of the antibodies used is expected to yield three bands, corresponding to the $46 \mathrm{kDa}$ and $52 \mathrm{kDa}$ forms of JNK 1, and the $54 \mathrm{kDa}$ form of both JNK2 and JNK3. Each experiment was repeated twice with similar results, and a representative blot is shown.

Real-time quantitative RT-PCR. For analysis of celastrol-induced changes in mRNA expression, utricles (three per condition) were incubated in $1.5 \mu \mathrm{M}$. celastrol for $3 \mathrm{~h}$ and allowed to recover for $0,3,5,8$, or $11 \mathrm{~h}$ in culture medium. Control and celastrol-treated utricles were stored in RNAlater RNA Stabilization Reagent (Qiagen, Valencia, CA, USA). Utricles were homogenized in a ground glass homogenizer (Wheaton Science, Millville, NJ, USA), and total RNA was collected using RNeasy Micro (Qiagen). RNA was reverse transcribed using random hexamer primers (TaqMan, Applied Biosystems), and the resulting CDNA was used for SYBR Green (Applied Biosystems) real-time PCR amplification of HSP70, HSP32, HSP90, HSP27, Nrf2, Gstm1, NQ01, UGT, and GCLC. Primer sets are detailed in Table 1. All mRNA analyses were performed in triplicate, and results are reported as fold changes in mRNA levels relative to control (untreated) utricles for each triplicate (mean \pm S.E.M.)

Hair cell counts. A double-label immunochemistry protocol using calmodulin and calbindin was used for quantification of hair cell density by epi-fluorescence microscopy, as previously described. ${ }^{13}$ In addition anti-Myosin Vlla labeling of utricles was used to determine hair cell density by confocal microscopy. Cultured utricles were fixed in $4 \%$ paraformaldehyde overnight at $4^{\circ} \mathrm{C}$. After fixation utricles were washed in $0.1 \mathrm{M}$ Sorenson's Phosphate Buffer $\left(40 \mathrm{mM} \mathrm{Na} 2 \mathrm{HPO}_{4} / 95 \mathrm{mM}\right.$ $\mathrm{NaH}_{2} \mathrm{PO}_{4} ; \mathrm{pH}$ 7.4) at room temperature. Otoconia were removed using Cal-Ex (Fisher Scientific, Pittsburg, PA, USA) for 2 min at room temperature followed by washes with $0.1 \mathrm{M}$ Sorenson's Phosphate Buffer. Utricles were then treated for

Table 1 Primer sets used for quantitative real-time PCR analyses

\begin{tabular}{|c|c|c|}
\hline Gene & Forward primer & Reverse primer \\
\hline $\begin{array}{l}\text { HSP70 } \\
\text { HSP32 } \\
\text { HSP90 } \\
\text { HSP27 } \\
\text { Nrf2 } \\
\text { Gstm1 } \\
\text { NQO1 } \\
\text { UGT } \\
\text { GCLC } \\
\text { 18s }\end{array}$ & $\begin{array}{l}\text { 5'-AGGCCAGGGCTGGTATTACT-3' } \\
\text { 5'-CTCACAGATGGCGTCACTTCGTCA-3' } \\
\text { 5'-GTGCGTGTTCATTCAGCCAC-3' } \\
\text { 5'-GAGAACCGAACGACCGTCC-3 } \\
\text { 5'-CAGTCTTCACTGCCCCTCAT-3' } \\
\text { 5'-CCTATGATACTGGGATACTGGAACG-3' } \\
\text { 5'-GCAGGATTTGCCTACACAATATGC-3' } \\
\text { 5'-GAAGCCTATGTCAACGCC-3' } \\
\text { 5'-ATCCTCCAGTTCCTGCACAT-3' } \\
\text { 5'-TTCGGAACTGAGGCCATGATT-3' }\end{array}$ & $\begin{array}{l}\text { 5'-AATGACCCGAGTTCAGGATG-3' } \\
\text { 5'-TTGCCAACAGGAAGCTGAGA-3' } \\
\text { 5'-GCAATTTCTGCCTGAAAGGC-3' } \\
\text { 5'-CCCAATCCTTTGACCTAACGC-3' } \\
\text { 5'-TCTGTCAGTGTGGCTTCTGG-3' } \\
\text { 5'-GGAGCGTCACCCATGGTG-3' } \\
\text { 5'-AGTGGTGATAGAAAGCAAGGTCTTC-3' } \\
\text { 5'-GCATCATCACCATCGGAA-3' } \\
\text { 5'-TGTGAATCCAGGGCA-3' } \\
\text { 5'-TTTCGCTCTGGTCCGTCTTG-3' }\end{array}$ \\
\hline
\end{tabular}


$10 \mathrm{~min}$ at room temperature with $1 \%$ sodium borohydride (Sigma). Utricles were washed again in $0.1 \mathrm{M}$ Sorenson's Phosphate Buffer, followed by a 3-h incubation in blocking solution $(0.5 \%$ fish gelatin $/ 1 \%$ bovine serum albumin $/ 0.5 \%$ Triton X-100 in PBS). Anti-Myosin VIla (MYO7A 138-1 from the Developmental Studies Hybridoma Bank, lowa City, IA, USA; 1:80) was diluted in blocking solution. Utricles were incubated in primary antibody overnight at $4^{\circ} \mathrm{C}$, followed by washes with blocking solution. Utricles were then incubated in Alexa 488-conjugated goat anti-mouse IgG (Invitrogen; 1:500) diluted in blocking solution for $3 \mathrm{~h}$ in the dark at room temperature. Utricles were washed again in blocking solution and mounted on glass slides using Fluoromount-G (Southern Biotech, Birmingham, AL, USA). Utricles were visualized using a Zeiss Axioplan 2 epi-fluorescent microscope (Carl Zeiss Microimaging, Thornwood, NY, USA), and images were captured using a highresolution monochrome digital camera (Zeiss Axiocam MR) and imaging software (Zeiss AxioVision). Hair cell counts were performed as previously described. ${ }^{13}$ Briefly, hair cells were counted in each of 4-5 extrastriolar $900 \mu \mathrm{m}^{2}$ areas. These counts were averaged for each utricle and reported as hair cell densities (hair cells per unit area). Some utricles were imaged using a Zeiss LSM 510 LSCM equipped with a $\times 63$ oil objective and $\times 2$ digital zoom.

Whole mount cochlea half-turns. Cochlear hair cells were labeled using a protocol described previously by Taleb et al. ${ }^{15}$ Cochleas were removed and perfused with ice cold $4 \%$ paraformaldehyde for fixation. After perfusion, cochleas were further incubated in $4 \%$ paraformaldehyde for $2 \mathrm{~h}$ at room temperature. After fixation cochleas were washed for $30 \mathrm{~min}$ in PBS before incubation in $0.5 \mathrm{M}$ EDTA with stirring for 3 days at room temperature. Cochleas were washed with PBS and bisected along the mid-modiolar plane using a piece of single-edge razor blade secured in a hemostat. All of the subsequent steps were carried out at $4{ }^{\circ} \mathrm{C}$ on a nutator. Cochlear halves were incubated in $30 \%$ hydrogen peroxide/water/PBS/ methanol at a ratio of $1 / 3 / 5 / 1$ for $2.5 \mathrm{~h}$ to quench endogenous peroxidases. Cochleas were then incubated in blocking solution ( $2 \%$ bovine serum albumin $/ 0.8 \%$ normal goat serum $/ 0.4 \%$ Triton- $X$ in PBS) overnight. Cochleas were incubated for 4 days with a polyclonal anti-Myosin VIla antibody (Proteus BioSciences Inc. \#25-6790, Ramona, CA, USA; 1:30 diluted in blocking solution) to label hair cells. Cochleas were next washed with blocking solution for $4 \mathrm{~h}$. Biotinylated goat antirabbit secondary antibody (Vector Laboratories Inc. \#PK-4001, Burlingame, CA, USA) was diluted 1:100 in blocking solution and cochleas were incubated overnight. Following secondary antibody incubation, cochleas were washed with PBS and then incubated in ABC (Vector Labs \#PK-4001) overnight. After washing, cochleas were incubated in buffer (Vector Laboratories Inc. \#SK-4100) for $20 \mathrm{~min}$ before incubation in diaminobenzidine (Vector Laboratories Inc. \#SK-4100) for $6 \mathrm{~h}$. Cochleas were then washed once more in PBS before the fine tissue preparation. A microscalpel and iridectomy scissors were used to dissect cochlear halves into apical, middle, and basal half-turns. The osseous spiral lamina, modiolus, stria vascularis, and tectorial membrane were removed, and cochlear half-turns were mounted on glass slides using Fluoromount-G.

Nrf2 localization. Utricles were cultured as above and exposed to $1.5 \mu \mathrm{M}$. celastrol for $3 \mathrm{~h}$ and allowed to recover for $3 \mathrm{~h}$. Control utricles were maintained in culture medium. Utricles were then fixed in $4 \%$ paraformaldehyde for $1 \mathrm{~h}$ at room temperature, followed by three washes in PBS and $3 \mathrm{~h}$ in blocking solution at room temperature. The tissue was incubated in primary antibody against Nrf2 (abCam \#31163; 1 : 100), diluted in blocking solution, overnight at $4^{\circ} \mathrm{C}$. Utricles were washed three times in blocking solution before being incubated in Alexa 488-conjugated goat anti-rabbit IgG (Invitrogen; 1:500) for $3 \mathrm{~h}$ at room temperature. Utricles were washed again in blocking solution, and incubated in Hoechst (Millipore; $1.25 \mu \mathrm{g} / \mathrm{ml}$ ) for $5 \mathrm{~min}$ at room temperature to label nuclei. Utricles were mounted as above. Confocal images were obtained using a Zeiss 510 META LSCM. Identical settings for pinhole size, gain, offset, and zoom were used for imaging utricles. For each of two experiments, fluorescence intensity from five random hair cells in each condition (nuclei and whole cells) was quantified using Adobe Photoshop.

Systemic celastrol and kanamycin treatments. A reliable protocol for aminoglycoside-induced hearing loss in mice has been established using the aminoglycoside kanamycin. ${ }^{42}$ Celastrol was dissolved in DMSO at a concentration of $10 \mathrm{mg} / \mathrm{ml}$. Mice received an initial injection of celastrol $(4 \mathrm{mg} / \mathrm{kg}$ of body weight, i.p.) diluted in $0.25 \mathrm{ml}$ of vehicle ( $40 \%$ cremophor/ethanol $3: 1 ; 60 \% \mathrm{PBS}), 12 \mathrm{~h}$ before the first kanamycin injection. Control mice received vehicle alone. Kanamycin was purchased from USB Corporation (Cleveland, OH, USA). Manufacturer's specifications estimated the purity of kanamycin base at $76.5 \%$, after correction for water and sulfate. Kanamycin powder base was dissolved in $0.9 \%$ sterile sodium chloride (saline) (Hospira, Lake Forest, IL, USA) to get a solution of concentration $52.3 \mathrm{mg} / \mathrm{ml}$. This concentration allowed $800 \mathrm{mg} / \mathrm{kg}$ of kanamycin (adjusted for water and sulfate) to be delivered subcutaneously to each animal at $0.02 \mathrm{ml} / \mathrm{g}$ of body weight. Control mice received saline alone. After the initial celastrol injection, mice were administered once daily injections of celastrol (or vehicle) each morning, followed immediately by an injection of kanamycin (or saline). At $8 \mathrm{~h}$ after the morning injections, mice received an additional kanamycin injection, totaling three daily injections (one celastrol and two kanamycin) for each of 14 days. ${ }^{42}$ In general, mice tolerated both celastrol and kanamycin, although one animal receiving kanamycin expired. ABR post-test analysis was performed 3 weeks after the final injection.

Auditory brainstem response. ABRs of adult CBA/J mice were recorded before receiving injections of celastrol and kanamycin. Mice were anesthetized with an intraperitoneal injection of $100 \mathrm{mg} / \mathrm{kg}$ ketamine hydrochloride (Fort Dodge Animal Health, Dodge, 10, USA) and $2 \mathrm{mg} / \mathrm{kg}$ xylazine hydrochloride (Ben Venue Laboratories, Bedford, OH, USA). All recordings were performed in a sound-isolated chamber, and mice were placed on a warming pad (Deltaphase Isothermal Pad, Braintree Scientific, Braintree MA, USA) to maintain body temperature. ABR testing equipment was purchased from Intelligent Hearing Systems (Miami, FL, USA). ABR recordings were captured by subdermal needle electrodes (FE-7 Grass Technologies, West Warwick, RI, USA) placed as follows: (1) non-inverting electrode at the vertex of the mid-line, (2) inverting electrode over the mastoid of the right ear, and (3) the common electrode on the upper thigh. Stimulus tones were presented at a rate of 19.3/s in free field via a high-frequency transducer (Intelligent Hearing Systems). Responses were filtered at $300-3000 \mathrm{~Hz}$. Stimulus intensity was decreased in $10 \mathrm{~dB}$ steps until a response waveform could no longer be identified. Subsequently stimulus intensity was increased in $5 \mathrm{~dB}$ steps until a waveform could again be identified. Suprathreshold responses were used as a comparison for determination of the threshold response. Threshold levels were determined from 1024 stimulus presentations, for at least two trials, and all thresholds were determined by a certified audiologist. Animals showing no response to stimulus presentations at the maximum output limits of the transducer were assigned threshold values of $5 \mathrm{~dB}$ greater than the output limit of the equipment. All animals were euthanized without recovery from anesthesia after final post-test completion.

Statistical analyses. Data were analyzed by ANOVA with Tukey's multiple comparisons for post hoc tests. $P$-values $<0.05$ were considered statistically significant. All error bars represent \pm standard error of the mean (S.E.M).

\section{Conflict of Interest}

The authors declare no conflict of interest.

Acknowledgements. This work was supported by the National Institutes of Health (NIDCD 5R01 DC007613, DC007613-SI, and 5F31 DC010559). Additional support was provided by the Division of Intramural Research at the National Institute on Deafness and Other Communication Disorders, NIH/NCRR extramural research facilities construction (C06) Grants C06 RR015455 and C06 RR14516 from the National Center for Research Resources, and the MUSC Initiative for Maximizing Student Diversity (IMSD) Program. We thank Dr. Margaret Lomax for providing us with $\mathrm{Hsf-1^{-1 }}$ mice. We also thank Dr. Thomas Friedman, Dr. Olivia BerminghamMcDonogh and Dr. Christina Voelkel-Johnson for helpful comments on the manuscript, and Lisa M. Fennessy for assistance in the development of the diagram of the mechanism of celastrol's protective effect.

1. Selimoglu E. Aminoglycoside-induced ototoxicity. Curr Pharm Des 2007; 13: 119-126.

2. Forge A, Li L. Apoptotic death of hair cells in mammalian vestibular sensory epithelia. Hear Res 2000; 139: 97-115.

3. Cunningham LL, Cheng AG, Rubel EW. Caspase activation in hair cells of the mouse utricle exposed to neomycin. J Neurosci 2002; 22: 8532-8540.

4. Matsui JI, Gale JE, Warchol ME. Critical signaling events during the aminoglycosideinduced death of sensory hair cells in vitro. J Neurobiol 2004; 61: 250-266.

5. Rybak LP, Ramkumar V. Ototoxicity. Kidney Int 2007; 72: 931-935.

6. Hirose K, Hockenbery DM, Rubel EW. Reactive oxygen species in chick hair cells after gentamicin exposure in vitro. Hear Res 1997; 104: 1-14. 
7. Pirvola U, Xing-Qun L, Virkkala J, Saarma M, Murakata C, Camoratto AM et al. Rescue of hearing, auditory hair cells, and neurons by CEP-1347/KT7515, an inhibitor of c-Jun $\mathrm{N}$-terminal kinase activation. J Neurosci 2000; 20: 43-50.

8. Priuska EM, Schacht J. Formation of free radicals by gentamicin and iron and evidence for an iron/gentamicin complex. Biochem Pharmacol 1995; 50: 1749-1752.

9. Sha SH, Schacht J. Antioxidants attenuate gentamicin-induced free radical formation in vitro and ototoxicity in vivo: D-methionine is a potential protectant. Hear Res 2000; 142: $34-40$.

10. Wang J, Van De Water TR, Bonny C, de Ribaupierre F, Puel JL, Zine A et al. A peptide inhibitor of $c$-Jun $\mathrm{N}$-terminal kinase protects against both aminoglycoside and acoustic trauma-induced auditory hair cell death and hearing loss. J Neurosci 2003; 23: 8596-8607.

11. Morimoto RI. Regulation of the heat shock transcriptional response: cross talk between family of heat shock factors, molecular chaperones, and negative regulators. Genes Dev 1998; 12: 3788-3796.

12. Yoshida N, Kristiansen A, Liberman MC. Heat stress and protection from permanent acoustic injury in mice. J Neurosci 1999; 19: 10116-10124.

13. Cunningham LL, Brandon CS. Heat shock inhibits both aminoglycoside- and cisplatininduced sensory hair cell death. J Assoc Res Otolaryngol 2006; 7: 299-307.

14. Taleb M, Brandon CS, Lee FS, Lomax MI, Dillmann WH, Cunningham LL et al. Hsp70 inhibits aminoglycoside-induced hair cell death and is necessary for the protective effect of heat shock. J Assoc Res Otolaryngol 2008; 9: 277-289.

15. Taleb M, Brandon CS, Lee FS, Harris KC, Dillmann WH, Cunningham LL et al. Hsp70 inhibits aminoglycoside-induced hearing loss and cochlear hair cell death. Cell Stress Chaperones 2009; 14: 427-437.

16. Kim HJ, So HS, Lee JH, Lee JH, Park C, Park SY et al. Heme oxygenase-1 attenuates the cisplatin-induced apoptosis of auditory cells via down-regulation of reactive oxygen species generation. Free Radic Biol Med 2006; 40: 1810-1819.

17. Maines MD. Heme oxygenase: function, multiplicity, regulatory mechanisms, and clinical applications. FASEB J 1988; 2: 2557-2568.

18. Lagendijk JJ. Hyperthermia treatment planning. Phys Med Biol 2000; 45: R61-R76.

19. Westerheide SD, Bosman JD, Mbadugha BN, Kawahara TL, Matsumoto G, Kim S et al. Celastrols as inducers of the heat shock response and cytoprotection. J Biol Chem 2004; 279: 56053-56060.

20. Allison AC, Allison AC, Cacabelos R, Lombardi VR, Alvarez XA, Vigo C et al. Celastrol, a potent antioxidant and anti-inflammatory drug, as a possible treatment for Alzheimer's disease. Prog Neuropsychopharmacol Biol Psychiatry 2001; 25: 1341-1357.

21. Yang H, Chen D, Cui QC, Yuan X, Dou QP. Celastrol, a triterpene extracted from the Chinese 'Thunder of God Vine,' is a potent proteasome inhibitor and suppresses human prostate cancer growth in nude mice. Cancer Res 2006; 66: 4758-4765.

22. Trott A, West JD, Klaić L, Westerheide SD, Silverman RB, Morimoto RI et al. Activation of heat shock and antioxidant responses by the natural product celastrol: transcriptional signatures of a thiol-targeted molecule. Mol Biol Cell 2008; 19: 1104-1112.

23. Lee JS, Surh YJ. Nrf2 as a novel molecular target for chemoprevention. Cancer Lett 2005; 224: 171-184.

24. Otterbein LE, Zuckerbraun BS, Haga M, Liu F, Song R, Usheva A et al. Carbon monoxide suppresses arteriosclerotic lesions associated with chronic graft rejection and with balloon injury. Nat Med 2003; 9: 183-190.

25. Raju VS, Maines MD. Coordinated expression and mechanism of induction of HSP32 (heme oxygenase-1) mRNA by hyperthermia in rat organs. Biochim Biophys Acta 1994; 1217: $273-280$

26. Hieronymus H, Lamb J, Ross KN, Peng XP, Clement C, Rodina A et al. Gene expression signature-based chemical genomic prediction identifies a novel class of HSP90 pathway modulators. Cancer Cell 2006; 10: 321-330.
27. Kobba S, Kim SC, Chen L, Kim E, Tran AL, Knuefermann P et al. The heat shock paradox and cardiac myocytes: role of heat shock factor. Shock 2011; 35: 478-484.

28. Theodore M, Kawai Y, Yang J, Kleshchenko Y, Reddy SP, Villalta F et al. Multiple nuclea localization signals function in the nuclear import of the transcription factor Nrf2. J Biol Chem 2008; 283: 8984-8994.

29. Yamashita K, Ollinger R, McDaid J, Sakahama H, Wang H, Tyagi S et al. Heme oxygenase- 1 is essential for and promotes tolerance to transplanted organs. Faseb J 2006; 20: $776-778$.

30. Orozco-Ibarra M, Estrada-Sánchez AM, Massieu L, Pedraza-Chaverr J. Heme oxygenase1 induction prevents neuronal damage triggered during mitochondrial inhibition: role of $\mathrm{CO}$ and bilirubin. Int J Biochem Cell Biol 2009; 41: 1304-1314.

31. Bilban M, Haschemi A, Wegiel B, Chin BY, Wagner O, Otterbein LE et al. Heme oxygenase and carbon monoxide initiate homeostatic signaling. $J$ Mol Med 2008; 86: 267-279.

32. Yu C, Rahmani M, Dent P, Grant S. The hierarchical relationship between MAPK signaling and ROS generation in human leukemia cells undergoing apoptosis in response to the proteasome inhibitor Bortezomib. Exp Cell Res 2004; 295: 555-566.

33. Meriin AB, Yaglom JA, Gabai VL, Zon L, Ganiatsas S, Mosser DD et al. Protein-damaging stresses activate $\mathrm{c}$-Jun $\mathrm{N}$-terminal kinase via inhibition of its dephosphorylation: a novel pathway controlled by HSP72. Mol Cell Biol 1999; 19: 2547-2555.

34. Tao X, Cush JJ, Garret M, Lipsky PE. A phase I study of ethyl acetate extract of the chinese antirheumatic herb Tripterygium wilfordii hook $F$ in rheumatoid arthritis. J Rheumatol 2001; 28: 2160-2167.

35. Goldbach-Mansky R, Wilson M, Fleischmann R, Olsen N, Silverfield J, Kempf P et al. Comparison of Tripterygium wilfordii Hook $F$ versus sulfasalazine in the treatment of rheumatoid arthritis: a randomized trial. Ann Intern Med 2009; 151: 229-240, W49-51.

36. Ji SM, Li LS, Wen JQ, Sha GZ, Cheng Z, Cheng DR et al. Therapeutic effect of Tripterygium wilfordii on proteinuria associated with sirolimus in renal transplant recipients. Transplant Proc 2008; 40: 3474-3478.

37. Cunningham LL. The adult mouse utricle as an in vitro preparation for studies of ototoxicdrug-induced sensory hair cell death. Brain Res 2006; 1091: 277-281.

38. Matsui JI, Haque A, Huss D, Messana EP, Alosi JA, Roberson DW et al. Caspase inhibitors promote vestibular hair cell survival and function after aminoglycoside treatment in vivo. Neurosci 2003; 23: 6111-6122.

39. McMillan DR, Xiao X, Shao L, Graves K, Benjamin IJ. Targeted disruption of heat shock transcription factor 1 abolishes thermotolerance and protection against heat-inducible apoptosis. J Biol Chem 1998; 273: 7523-7528.

40. Hunt CR, Dix DJ, Sharma GG, Pandita RK, Gupta A, Funk M et al. Genomic instability and enhanced radiosensitivity in Hsp70.1- and Hsp70.3-deficient mice. Mol Cell Biol 2004; 24: 899-911.

41. Wright GD, Thompson, PR. Aminoglycoside phosphotransferases: proteins, structure, and mechanism. Front Biosci 1999; 4: D9-21.

42. Wu WJ, Sha SH, McLaren JD, Kawamoto K, Raphael Y, Schacht J. Aminoglycoside ototoxicity in adult CBA, C57BL and BALB mice and the Sprague-Dawley rat. Hear Res 2001; 158: 165-178.

Cell Death and Disease is an open-access journal published by Nature Publishing Group. This work is licensed under the Creative Commons Attribution-Noncommercial-No Derivative Works 3.0 Unported License. To view a copy of this license, visit http://creativecommons.org/licenses/by-nc-nd/3.0/ 